УДК 373.1

13.00.00 Педагогические науки

ФОРМИРОВАНИЕ ГОТОВНОСТИ БУДУЩЕГО ЭСТРАДНОГО ВОКАЛИСТА К КОНЦЕРТНОЙ ДЕЯТЕЛЬНОСТИ: ЭКСПЕРИМЕНТАЛЬНОЕ ИССЛЕДОВАНИЕ

Куко (Широкова) Светлана Сергеевна

Сотрудник

в/ч 84841, г.-к. Анапа, Россия

Статья посвящена экспериментальному исследованию процесса формирования готовности будущего эстрадного вокалиста к концертной деятельности. В ней представлена теоретическая модель формирования исследуемого феномена, разработанная автором статьи, включающая следующие блоки: концептуально-целевой, содержательнодеятельностный, организационнотехнологический, оценочно-результативный. В статье рассмотрены принципы и методы формирования исследуемой готовности, представлены этапы педагогического эксперимента: диагностический, поисковый, направленный на формирование педагогического репертуара, формирующий (основной), на котором осуществлялась опытная работа в экспериментальной группе с целью проверки эффективности разработанной теоретической модели и педагогических условий формирования исследуемой готовности. Заключительный (контрольный) этап интегрировал на художественно-творческом уровне профессиональную подготовку эстрадного вокалиста. В качестве показателей готовности будущего эстрадного вокалиста к концертной деятельности были рассмотрены мотивационнопотребностный, эмоционально-креативный, рефлексивный, художественно-операциональный компоненты. Результаты экспериментального исследования подтвердили эффективность разработанных педагогических условий, среди которых: обеспечение развития художественнотворческого потенциала студента, овладение вокальным мастерством, спецификой эстрадноджазового исполнительства, актерским мастерством, индивидуальной манерой пения, развитие общих и музыкальных способностей, создание позитивной психологической установки и овладение навыками саморегуляции, рефлексии, освоение звукоусиливающей аппаратуры. Полученные данные дополняют и конкретизируют систему обучения и подготовки студентов эстрадно-джазового пения в вузах культуры и искусств

Ключевые слова: ГОТОВНОСТЬ, КОНЦЕРТНАЯ
UDC 373.1

Pedagogical science

\section{FORMATION OF READINESS OF FUTURE POP SINGER'S CONCERT ACTIVITY: A PILOT STUDY}

\author{
Cuco (Shirokova) Svetlana Sergeevna \\ Employee \\ Military office 84841, Anapa, Russia
}

The article is devoted to the experimental study of the process of formation of readiness of the future pop singer to the concert activity. It presents a theoretical model of the phenomenon under study, developed by the author, including the following components: a conceptual and targeted, meaningful activity-related, organizational, technological, assessment and effective. The article describes the principles and methods of formation investigated readiness illustrates steps pedagogical experiment: diagnostic, search, aimed at forming pedagogical repertoire forming (main), which was carried out experimental work in the experimental group to verify the efficiency of the developed theoretical models and pedagogical formation conditions investigated readiness. The final (control) stage integrated in the artistic and creative level training pop singer. As indicators of readiness of the future pop singer to the concert activities were considered need-motivational, emotional and creative, reflective, artistic and operational components The results of the experimental study confirmed the effectiveness of the developed pedagogical conditions, including: ensuring the development of the artistic and creative potential of the student, mastering the vocal skill, the specificity of variety and jazz performance, acting skills, individual style of singing, developing general and musical abilities, creating a positive psychological attitude and mastering skills Selfcontrol, reflection, development of sound reinforcement equipment. The received data supplement and specify the system of training and preparation of students of variety jazz singing in universities of culture and arts 
ДЕЯТЕЛЬНОСТЬ, ЭСТРАДНЫЙ ВОКАЛИСТ, ПЕДАГОГИЧЕСКИЕ УСЛОВИЯ, ДИАГНОСТИКА

\section{Doi: $10.21515 / 1990-4665-130-080$}

Качество вокальной подготовки будущего эстрадного вокалиста связано с большим количеством факторов, среди которых важную роль играет готовность к концертной деятельности, способность регулировать психоэмоциональное состояние перед выступлением и во время него. Как ранее отмечал автор статьи: «Формирование готовности эстрадного вокалиста к концертным выступлениям - это сложный системный процесс, представляющий собой совокупность певческих и творческих навыков и требующий эмоционально-психологической, теоретической и практической подготовки к концертному выступлению» [1, с. 104].

Эстрадно-джазовое исполнительство имеет свою специфику, связанную с манерой звукоизвлечения, особой ритмической организацией, импровизационностью, экспрессией. Исследование различных материалов по данной проблеме дало возможность создать теоретическую модель формирования исследуемого феномена, представляющую собой совокупность четырех разделов-блоков: концептуально-целевого, содержательно-деятельностного, организационно-технологического, оценочно-результативного [2].

Концептуально-целевой блок включает следующие компоненты: цель, задачи, а также методологические подходы и принципы формирования готовности будущего эстрадного вокалиста к концертной деятельности. Общепринятые принципы подготовки вокалистов изложены в разных источниках, в частности, Г.П. Стуловой. Среди них - принципы постепенности, последовательности и непрерывности, заинтересованности и сознательности, направленности и перспективности, единства художественного и технического, индивидуального подхода и др. [3]. 
Автором статьи также были выделены специальные принципы подготовки студентов к концертным выступлениям: креативности, интеграции форм творческой деятельности.

Содержательно-деятельностный блок теоретической модели включает такие компоненты как вокально-техническое мастерство (вокальную технику, эстрадно-джазовую артикуляцию, постановку дыхательного аппарата); овладение оригинальной индивидуальной манерой исполнения, актерским мастерством, спецификой сценического движения. Данный блок также предполагает развитие общих и музыкальных способностей вокалистов (музыкального слуха, мышления, памяти, воображения, чувства ритма), а также сценических способностей, навыков анализа, интерпретации вокальных сочинений.

Организационно-технологический блок теоретической модели содержит этапы формирования исследуемого феномена: диагностический, поисковый, формирующий, художественно-творческий, также различные формы обучения: индивидуальные, мелкогрупповые, концертные выступления. Во всех формах работы предполагается использование элементов самокоррекции, аутотренинга, технологий сотрудничества, обсуждение достоинств и недостатков выступлений.

Завершает теоретическую модель оценочно-результативный блок, позволяющий оценить эффективность разработанной модели по следующим компонентам: мотивационно-потребностному, эмоциональнокреативному, рефлексивному, художественно-операциональному.

Педагогический эксперимент был направлен на проверку эффективности теоретической модели и разработанных педагогических условий формирования готовности будущего эстрадного вокалиста к концертной деятельности. Для этой цели использовался ряд экспериментальных методов, в том числе метод экспертных оценок. В качестве экспертов были приглашены преподаватели эстрадно-джазового 
искусства, члены жюри конкурсов различного уровня, которые выставляли в специально разработанных таблицах экспертные оценки. Далее учитывались мнения всех экспертов, которые позволили выявить средние показатели по всем исследуемым компонентам. С экспертами были проведены беседы, в которых они давали ту или иную оценку, описывали свои впечатления о прослушанном выступлении. Выводы экспертов позволили в дальнейшем определить степень готовности студентов к концертным выступлениям.

Экспериментальной базой исследования был Краснодарский государственный университет культуры и искусств (в 2015 году переименованный в федеральное государственное бюджетное образовательное учреждение высшего образования «Краснодарский государственный институт культуры»). В педагогическом эксперименте были задействованы студенты 1-4 курсов специальности «Эстрадноджазовый вокал». Были определены контрольная и экспериментальная группы по 8 человек в каждой.

В ходе педагогического эксперимента решались следующие задачи: разработка диагностических процедур определения уровня сформированности компонентов исследуемой готовности, проверка эффективности теоретической модели и педагогических условий формирования готовности студентов эстрадно-джазового вокала к концертной деятельности.

Руководствуясь принципами формирования готовности будущего эстрадного вокалиста к концертной деятельности, автором были спланированы этапы проводимого экспериментального исследования: 1) диагностический, направленный на выявление уровня сформированности компонентов готовности будущего эстрадного певца к концертной деятельности; 2) поисковый, ориентированный на создание творческого репертуара, наиболее соответствующего уровню подготовки и 
возможностям вокалиста, художественный анализ поэтического и музыкального текста; 3) формирующий этап, направленный на профессиональную художественную подготовку эстрадно-джазового вокалиста, включающую множество аспектов, в том числе: работу над вокальной техникой, исполнительский анализ вокального сочинения, психологическую готовность к сценическому воплощению художественного произведения; 4) заключительного этап художественно-творческий, интегрирующий все предыдущие этапы, направленный на творческую интерпретацию эстрадно-джазового сочинения в условиях концертного выступления, включающего работу с микрофоном.

Диагностика готовности студентов к концертной деятельности включала проверку вышеуказанных компонентов: мотивационнопотребностного, эмоционально-креативного, когнитивно-рефлексивного, художественно-операционального. Эти компоненты характеризуют направленность личности исполнителя на совершенствование вокальносценической подготовки, эмоционально выраженный, творческий подход к процессу подготовки, а также осознанное, яркое, профессионально выверенное воплощение художественного образа исполняемого произведения эстрадно-джазового искусства. В ходе подготовки к экспериментальному исследованию готовности будущего эстрадного вокалиста к концертной деятельности были разработаны критерии и показатели по каждому компоненту данной готовности, отражающие высокий, средний и низкий уровни.

Для выявления уровня сформированности каждого из компонентов исследуемого феномена использовались разнообразные творческие задания, проводилось анкетирование, исследовалось качество выполнения самостоятельной работы. Проведенная диагностика уровня сформированности мотивационно-потребностного, эмоционально- 
креативного, когнитивно-рефлексивного,

операционального компонентов подтвердила художественно-

равноценность экспериментальной и контрольной групп.

Диагностика компонентов исследуемой готовности на констатирующем этапе показала, что только $44 \%$ студентов ориентированы на самостоятельную работу; 66\% испытуемых обращают особое внимание на процесс подготовки к концертным выступлениям. Большинство студентов настроены позитивно на процесс обучения, проявляют искреннюю заинтересованность в подготовке к концертным выступлениям, в то же время 33\% обучающихся показали некоторое разочарование, безразличие. Все без исключения респонденты (100 \%) обращают внимание на то, как реагирует публика на их выступление, многие из них стараются развивать в себе навыки рефлексии. Вместе с тем результаты диагностики показали, что в отдельной проверке нуждается такое качество студентов как способность к адекватной самооценке своей концертной деятельности.

В целом, данные, полученные в ходе диагностического этапа, показали, что еще есть студенты, у которых мотивационно-потребностный компонент находится на низком уровне (по $37,5 \%$ в ЭГ и КГ), а на высоком уровне оказался только 1 студент контрольной группы (12,5\%).

Уровень эмоционально-креативного компонента проверялся $\mathrm{c}$ помощью творческого задания, направленного на самостоятельное изучение джазового стандарта Arthur Hamilton «Cry me a river». Экспертная группа обращала внимание на качество выполнения данного задания студентами: творческий подход, креативность, вокальная техника, артистизм. Обобщенные данные экспертов показали, что данный компонент сформирован еще недостаточно, о чем свидетельствовал также контент-анализ проведенного анкетирования. Низкий уровень показали $62,5 \%$ студентов ЭГ и $50 \%$ КГ. 
Следующий компонент исследуемой готовности - когнитивнорефлексивный - проверялся с помощью анализа и самоанализа уровня вокальной и теоретической подготовки. Как показало исследование, только один студент экспериментальной группы продемонстрировал достаточно высокий уровень самооценки своей концертной деятельности.

Одним из важных компонентов готовности эстрадного вокалиста к концертной деятельности является художественно-операциональный, который характеризует креативность исполнителя, умение адекватно интерпретировать вокальное сочинение, владение тонкостями эстрадноджазового исполнения. Для проверки уровня сформированности данного компонента студентам было предложено подготовить два концертных номера в течение двух недель. При прослушивании им было предложено исполнить только одно произведение, а через некоторое время - исполнить и второе произведение, к чему они были не совсем готовы. В данном случае проверялось отсроченное воспроизведение в определенной ситуации, когда студенты должны были сориентироваться и качественно исполнить вторую композицию. Как и прежде, результаты подготовки оценивала экспертная комиссия. В ЭГ и КГ 62,5 \% студентов показали низкий уровень по художественно-операциональному компоненту.

Таким образом, как показывают исследования, на диагностическом этапе уровень сформированности готовности студентов к концертной деятельности был еще недостаточный, что означает необходимость целенаправленной работы. Также были выявлены студенты с завышенной самооценкой, что свидетельствует о том, что они не совсем готовы повышать уровень вокального мастерства и сценической подготовки. Были студенты и с заниженной самооценкой, что также говорит о проблемах профессиональной подготовки. 
На поисковом этапе в экспериментальной группе особое внимание обращалось на совершенствование творческого репертуара студентов с учетом уровня их подготовки, задач исследования, требований рабочей программы дисциплины. При этом в процессе формирования художественного репертуара учитывались свойства темперамента студента. Флегматикам и меланхоликам предлагались произведения жизнерадостные, а холерикам и сангвиникам - более спокойные, лирические произведения, что позволяло расширить творческий репертуар вокалистов. Специальная работа проводилась по исполнительскому анализу вокальных сочинений, изучению особенностей литературного и музыкального текстов.

Основной - формирующий этап - проводился в течение двух учебных годов. В экспериментальной группе были созданы все условия для эффективной подготовки студентов к концертной деятельности, учитывались разработанные автором педагогические условия формирования исследуемой готовности: «1) обеспечение непрерывного развития творческого, художественного, исполнительского потенциала и организация художественно-творческой среды; 2) овладение вокальным мастерством (формирование вокальной техники, дыхательного аппарата и эстрадно-джазовой артикуляции), индивидуальной манерой пения (оригинально-индивидуальной интерпретацией исполняемых сочинений); 3) освоение актерского мастерства (способности театрализованного исполнения, полного включения в художественный образ), навыков сценического движения (эстрадной хореографии, пластичности и ритмичности движений); 4) совершенствование музыкальных способностей (музыкального слуха, чувства ритма), познавательных процессов (творческого внимания, воображения, музыкального мышления, памяти), аналитических способностей; 5) руководство специальными принципами и методами обучения; 6) создание позитивной 
психологической установки и овладение навыками саморегуляции, рефлексии; 6) освоение звукоусиливающей аппаратуры» [4].

В процессе подготовки эстрадных выступлений в экспериментальной группе мы стремились создавать творческую атмосферу, позитивную психологическую установку, обеспечивать непрерывное развитие исполнительского, художественного, творческого потенциала вокалиста. Среди используемых методов в экспериментальной группе были: методы моделирования концертной ситуации, театрализации, целостного анализа нотного текста, ролевой подготовки, мысленного «пропевания» произведения в определенном тонусе. Особое значение уделялось хореографическим занятиям, актерскому мастерству, творческой интерпретации вокальной программы, прослушиванию лучших образцов эстрадно-джазового искусства.

В контрольной группе занятия проводились по традиционной методике, в соответствии с учебным планом. На заключительном этапе была проведена повторная диагностика в экспериментальной и контрольной группах по всем компонентам формируемой готовности по аналогичным творческим и другим заданиям. Результаты диагностики показали рост всех показателей в обеих группах, однако в контрольной группе результаты исследования были более скромными: 37,5-50 \% оказались на высоком уровне по разным компонентам, в то время как в экспериментальной группе по этим же показателям было 75-87,5 \% студентов. В контрольной группе не все студенты показали достаточно высокие результаты по уровню сформированности художественнооперационального и когнитивно-рефлексивного компонентов.

Студенты экспериментальной группы обнаружили в целом более высокий, творческий уровень вокальной подготовки к концертному выступлению, проявили стрессоустойчивость, артистизм. Проведенный педагогический эксперимент подтвердил эффективность теоретической 
модели и разработанных педагогических условий формирования

готовности студентов эстрадно-джазового вокала к концертной

деятельности. В своих выступлениях студенты экспериментальной группы

смогли расширить границы своих возможностей, приобрести

профессиональные навыки, уверенность в своем творческом потенциале.

\section{Литература}

1. Широкова, С. С. Готовность эстрадного певца к концерту / С. С. Широкова // Культурная жизнь Юга России. - 2011. - № 3 (41). - С. 104.

2.Широкова, С. С. Моделирование процесса формирования готовности будущего эстрадного вокалиста к концертной деятельности в вузе / Т. И. Стражникова, С. С. Широкова // Политематический сетевой электронный науч. журнал Кубанского гос. аграрного ун-та (Научный журнал КубГАУ) [Электронный ресурс]. - Краснодар: КубГАУ, 2013. - № 01(85). - Режим доступа: http://ej.kubagro.ru/2013/01/pdf/41.pdf . 0,625 у.П.л. (авторство неразделенное).

3. Стулова, Г. П. Дидактические основы обучения пению: учеб пособие / Г. П. Стулова. - М.: МГПИ им. В. И. Ленина, 1988. - С. 50-51.

4. Широкова, С. С. Педагогические условия формирования готовности будущего эстрадного вокалиста к концертной деятельности / Т. И. Стражникова, С. С. Широкова // Политематический сетевой электронный научный журнал Кубанского государственного аграрного университета (Научный журнал КубГАУ) [Электронный peсурс]. - Краснодар: КубГАУ, 2015. - № 112(08). - Режим доступа: http://ej.kubagro.ru/2015/10/pdf. - 0,625 у.п.л. (авторство неразделенное).

\section{References}

1. Shirokova, S. S. Gotovnost estradnogo pevtsa k kontsertu / S. S. Shirokova // Kulturnaya zhizn Yuga Rossii. - 2011. - \# 3 (41). - S. 104.

2.Shirokova, S. S., Strazhnikova T. I. Modelirovanie protsessa formirovaniya gotovnosti buduschego estradnogo vokalista k kontsertnoy deyatelnosti v vuze / T. I. Strazhnikova, S. S. Shirokova // Politematicheskiy setevoy elektronnyiy nauch. zhurnal Kubanskogo gos. agrarnogo un-ta (Nauchnyiy zhurnal KubGAU) [Elektronnyiy resurs]. Krasnodar: KubGAU, 2013. - \# 01(85). - Rezhim dostupa: http://ej.kubagro.ru/2013/01/pdf/41.pdf . - 0,625 u.p.l. (avtorstvo nerazdelennoe).

3. Stulova, G. P. Didakticheskie osnovyi obucheniya peniyu: ucheb posobie / G. P. Stulova. - M.: MGPI im. V. I. Lenina, 1988. - S. 50-51].

4. Shirokova, S. S. Pedagogicheskie usloviya formirovaniya gotovnosti buduschego estradnogo vokalista k kontsertnoy deyatelnosti / T. I. Strazhnikova, S. S. Shirokova // Politematicheskiy setevoy elektronnyiy nauchnyiy zhurnal Kubanskogo gosudarstvennogo agrarnogo universiteta (Nauchnyiy zhurnal KubGAU) [Elektronnyiy resurs]. - Krasnodar: KubGAU, 2015. - \# 112(08). - Rezhim dostupa: http://ej.kubagro.ru/2015/10/pdf. - 0,625 u.p.l. (avtorstvo nerazdelennoe). 